\title{
Métodos e temperaturas de hidratação na qualidade fisiológica de sementes de milho ${ }^{1}$
}

\author{
Methods and temperatures of hydration on physiological quality of corn seeds
}

\author{
Claudemir Zucareli ${ }^{2}$, Cláudio Cavariani ${ }^{3}$, Eliege Aparecida de Paiva Oliveira ${ }^{2 *}$ e João Nakagawa ${ }^{3}$
}

Resumo - O procedimento de uniformização e elevação do teor de água das sementes é recomendável para se obter resultados uniformes e confiáveis, em testes para a qualidade fisiológica de sementes, como o envelhecimento acelerado e a deterioração controlada. O trabalho teve como objetivo avaliar a qualidade fisiológica de sementes de milho, após a hidratação sob diferentes métodos e temperaturas, visando à elevação do teor de água para 15; 20 e 25\%. Empregou-se o delineamento inteiramente casualizado, em esquema fatorial 4 x 2, com quatro repetições. Os tratamentos foram constituídos de quatro métodos de hidratação (substrato úmido, atmosfera úmida, imersão em água e adição da quantidade de água requerida) sob duas temperaturas $\left(20\right.$ e $\left.30^{\circ} \mathrm{C}\right)$. Após a hidratação, as sementes foram submetidas às seguintes determinações: teor de água, condutividade elétrica, porcentagens de germinação e de plântulas normais na primeira contagem do teste de germinação, massas secas das porções aérea, radicular e total das plântulas obtidas na primeira contagem. O método da atmosfera úmida proporciona redução da qualidade fisiológica das sementes de milho nos três teores de água. A temperatura de $30{ }^{\circ} \mathrm{C}$ e o método da imersão direta em água não alteram a qualidade fisiológica das sementes de milho, mostrando-se adequados para a hidratação visando à elevação do teor de água para 15; 20 e 25\%.

Palavras-chave - Zea mays. Teor de água. Germinação. Potencial fisiológico.

\begin{abstract}
The procedure to standardize and increase the water content of seeds is recommended to achieve consistent results and reliable tests for the physiological quality of seeds, such as accelerated aging and controlled deterioration. The study aimed to evaluate the physiological quality of corn seeds after hydration under different methods and temperatures, in order to increase the water content to 15,20 and $25 \%$. Randomized design were employed completely in a factorial $4 \times 2$ with four replications. The treatments consisted of four methods of moisture (substrate damp, humid atmosphere, immersion in water and adding the required quantity of water) at two temperatures $\left(20\right.$ and $\left.30^{\circ} \mathrm{C}\right)$. After hydration, the seeds were subjected to the following parameters: water content, electrical conductivity, germination and normal seedlings in the first count of germination test, dry pasta portions of air, root and whole plant collected in the first count. The method provides a reduction of the moist atmosphere of the physiological quality of corn seeds in three levels of $30^{\circ} \mathrm{C}$ water temperature and the method of immersion in water does not alter the physiological quality of corn seeds, being suitable for hydration in order to high water content for $15 ; 20$ and $25 \%$.
\end{abstract}

Key words - Zea mays. Water content. Germination. Physiological potential.

\footnotetext{
*Autor para correspondência

${ }^{1}$ Recebido para publicação em 09/10/2011; aprovado 26/02/2011

Parte da Dissertação do primeiro autor, apresentada ao Departamento de Ciências Agronômicas da Universidade Estadual Paulista, financiada pela CAPES

${ }^{2}$ Departamento de Agronomia da Universidade Estadual de Londrina/UEL, Londrina-PR, Brasil, claudemircca@uel.br, paivaeliege@gmail.com

${ }^{3}$ Faculdade de Ciências Agronômicas/UNESP, Botucatu-SP, Brasil, ccavariani@fca.unesp.br, secdamv@fca.unesp.br
} 


\section{Introdução}

A absorção de água é a primeira etapa do processo de germinação, sendo diretamente influenciada por fatores ambientais como a disponibilidade de água e a temperatura, no entanto em sementes de milho suas diferentes partes constituintes absorvem água com velocidades similares (LIMA et al., 2006; VILLELA et al., 2003). Além desses fatores, o substrato utilizado também exerce influência sobre o processo de hidratação devido a características como o potencial hídrico e a capacidade de condução térmica (WAGNER JÚNIOR et al., 2006).

O processo de hidratação segue um padrão trifásico, sendo a água o regulador de fundamental importância no desenvolvimento e na germinação das sementes. A primeira fase é muito rápida, ocorrendo como conseqüência do potencial matricial de vários tecidos. $\mathrm{Na}$ segunda fase, a semente absorve água lentamente, estabelecendo-se o transporte ativo de substâncias desdobradas na fase anterior, do tecido de reserva para o tecido meristemático. Na terceira fase, torna-se visível a retomada do crescimento embrionário, ocorre similaridade de potenciais hídricos nos embriões e a protrusão da raiz primária (BEWLEY; BLACK, 1994; CARVALHO; NAKAGAWA, 2000; VILLELA et. al., 2003).

Sementes com baixo teor de água, quando colocadas em um substrato úmido ou em água para a embebição, apresentam inicialmente rápida e intensa perda de lixiviados, decrescendo à medida que os tecidos são reidratados, até atingir um ponto de equilíbrio (ROSA et al., 2000). Sob baixos conteúdos de água, a atividade metabólica da semente é baixa, fazendo-se necessária a reabsorção desta para que o seu metabolismo seja reativado. Paralelamente, as atividades metabólicas também aumentam, diminuindo o potencial interno, propiciando maior absorção de água.

$\mathrm{Na}$ fase de embebição, os embriões das sementes com menor potencial fisiológico absorvem quantidade de água superior aos de maior potencial fisiológico (VILLELA et al., 2003). Para Villela et. al., (2007), a absorção da água vem sendo descrita, quase que exclusivamente, com base na determinação do teor de água da semente e interpretação de seu significado biológico.

A velocidade de absorção de água pela semente depende da espécie, da composição química, da permeabilidade do tegumento, da disponibilidade de água, área de contato, temperatura (BECKERT; SILVA, 2002). Assim, pode-se dizer que o teor de água da semente difere acentuadamente entre espécies (GARNCZARSKA et al., 2007; KIKUCHI et al., 2006; MEYER et al., 2007; TERSKIKH et al., 2005), como também entre cultivares (VILLELA et al., 2003).
No caso especifico da semente de milho, McDonald et al. (1994) consideram que a embebição ocorre por dois diferentes caminhos: rápida entrada de água através da camada negra, levando à hidratação do embrião e pelo movimento de uma frente úmida que penetra no pericarpo avançando lentamente, através do endosperma. Desta forma, a entrada de água em sementes de milho é regulada por complexos fatores químicos (composição química) e físicos (anatomia).

Em determinados testes utilizados para a avaliação da qualidade fisiológica de sementes, como o envelhecimento acelerado e a deterioração controlada, o procedimento de uniformização e elevação do teor de água das sementes é recomendável ou obrigatório para se obter resultados uniformes e confiáveis. Considerando os diversos fatores atuantes no processo de hidratação das sementes, o estudo de métodos e metodologias de hidratação artificial, específicos para cada espécie, se faz necessário, de modo a estabelecer procedimentos que não alterem a qualidade das mesmas. Ademais, a necessidade de acesso à metodologia segura para hidratação artificial, de modo a inexistir alterações na qualidade fisiológica das sementes é também mencionada por Zucareli et al. (2008).

O objetivo do trabalho foi avaliar a qualidade fisiológica de sementes de milho após hidratação sob diferentes métodos e temperaturas, visando à elevação do teor de água para $15 ; 20$ e $25 \%$.

\section{Material e métodos}

O trabalho foi realizado no Laboratório de Análise de Sementes do Departamento de Produção Vegetal da Faculdade de Ciências Agronômicas (FCA), da Universidade Estadual Paulista (UNESP), em BotucatuSP. Foram utilizadas sementes comerciais de milho do híbrido $\mathrm{CO} 32$, peneira 20 , categoria $\mathrm{S} 1$, não tratadas. A avaliação da qualidade inicial do lote foi realizada pelas determinações de: Teor de água: foram utilizadas quatro repetições de 15 sementes inteiras sob o método da estufa a $105 \pm 3{ }^{\circ} \mathrm{C}$, durante 24 horas (BRASIL, 2009). Massa de mil sementes: determinada com oito repetições de 100 sementes, conforme descrito nas Regras para Análise de Sementes (BRASIL, 2009). Germinação: quatro repetições de 50 sementes, em papel toalha (germitest) umedecido na proporção de 2,5 vezes a massa do substrato. Os rolos de papel, acondicionados em sacos plásticos, foram mantidos em germinador sob temperatura de $30{ }^{\circ} \mathrm{C}$, sob fotoperíodo de 16 horas de luz. A avaliação constou de duas contagens do percentual de plântulas normais, aos quatro e sete dias após a instalação do teste (BRASIL, 2009). Primeira contagem de germinação: computando-se a porcentagem de plântulas normais obtidas no quarto dia após a instalação do teste de germinação (BRASIL, 2009). 
Teste de frio: conduzido utilizando-se a metodologia do rolo de papel sem solo, com quatro repetições de 50 sementes, os rolos permaneceram a $10{ }^{\circ} \mathrm{C}$ por sete dias, conforme descrito por Dias e Barros (1995). Após este período os rolos foram transferidos para câmara de $30^{\circ} \mathrm{C}$, por mais quatro dias para a contagem das plântulas normais. Teste de envelhecimento acelerado: utilizaram-se quatro repetições de 65 sementes envelhecidas a $42{ }^{\circ} \mathrm{C}$ por 72 horas (DIAS; BARROS, 1995), em caixa plástica (gerbox). Quatro repetições de 15 sementes foram utilizadas para determinação do teor de água e, quatro repetições de 50 sementes foram submetidas ao teste de germinação. Teste de condutividade elétrica: quatro repetições de 25 sementes, previamente pesadas, foram colocadas para embeber em $75 \mathrm{~mL}$ de água destilada, por um período de 24 horas a $25{ }^{\circ} \mathrm{C}$ (DIAS; BARROS, 1995), seguiu-se leve agitação e leitura $\left(\mu \mathrm{S} \mathrm{cm} \mathrm{cm}^{-1} \mathrm{~g}^{-1}\right)$ da condutividade elétrica da solução de embebição em condutivímetro. Teste de tetrazólio: conduzido empregando-se quatro repetições de 50 sementes conforme metodologia descrita por Dias e Barros (1995).

Emergência das plântulas no campo: conduzido com quatro repetições de 50 sementes, que foram semeadas a $5 \mathrm{~cm}$ de profundidade em linhas de 2,5 m, distanciadas de $0,30 \mathrm{~m}$ entre si. A avaliação foi realizada aos 14 dias após semeadura e o resultado expresso em porcentagem de plântulas emergidas (NAKAGAWA, 1994). Índice de velocidade de emergência (IVE): conduzido em conjunto com o teste de emergência de plântulas, foram realizadas contagens diárias, a partir da emergência da primeira plântula até o décimo quarto dia. O IVE foi calculado segundo Maguire (1962), citado por Nakagawa (1999). Massa seca de plântulas: as plântulas normais obtidas na primeira contagem do teste de germinação foram separadas em duas porções, parte aérea e radicular, secadas em estufa a $60 \pm 5^{\circ} \mathrm{C}$ até atingirem peso constante. A massa seca obtida, dividida pelo número de plântulas, expressou os resultados em gramas por plântula das porções aérea, radicular e total, nesse caso pela somatória das duas anteriores (NAKAGAWA, 1999).

O lote de sementes utilizado apresentou, inicialmente, alta geminação e vigor, mostrando-se adequado para uso na avaliação dos métodos e metodologias de hidratação de sementes de milho (TAB. 1).
Empregou-se o delineamento inteiramente casualizado, em esquema fatorial $4 \times 2$, com quatro repetições de 100 sementes por tratamentos. Os tratamentos foram constituídos de quatro métodos de hidratação (substrato úmido - SU, atmosfera úmida - AU, imersão em água - IA e adição de quantidade de água requerida - AR), sob duas temperaturas $\left(20\right.$ e $\left.30{ }^{\circ} \mathrm{C}\right)$. Considerou-se a elevação do teor de água das sementes para 15; 20 e 25\%, independente das temperaturas testadas.

A massa a ser atingida pelas amostras para se obter os teores de água de $15 ; 20$ e $25 \%$, em todos os métodos avaliados foram previamente determinadas tendo como base a massa e o teor de água inicial das mesmas (HAMPTON; TEKRONY, 1995).

No método do substrato úmido foi adotada a metodologia descrita por Zucareli et al. (2008) utilizando papel toalha (germitest) umedecido em água destilada nas proporções de 2,5 e 3,0 vezes a massa do papel para as temperaturas de $20 \mathrm{e} 30^{\circ} \mathrm{C}$. Os rolos foram acondicionados em sacos plásticos fechados e mantidos em câmara BOD, até atingirem a massa previamente determinada.

Para o método da atmosfera úmida, cada repetição foi disposta sobre tela metálica em caixas plásticas (gerbox), utilizadas para o teste de envelhecimento acelerado, contendo em seu interior $40 \mathrm{~mL}$ de água destilada, mantidas em câmaras BOD nas temperaturas estabelecidas até as sementes atingirem a massa previamente determinada.

No método da imersão em água as sementes foram colocadas em recipientes plásticos $(200 \mathrm{~mL})$, imersas em $100 \mathrm{~mL}$ de água destilada e mantidas em câmara tipo BOD nas temperaturas de 20 e $30{ }^{\circ} \mathrm{C}$ até atingirem a massa previamente determinada.

Para o método da adição de água requerida, a quantidade de água a ser adicionada a amostra, para se atingir os teores de água desejados $(15 ; 20$ e $25 \%)$ foram determinadas considerando-se a massa e o teor de água inicial das sementes para cada repetição. As sementes foram acondicionadas em frascos plásticos com as quantidades de água previamente calculadas e mantidas em câmaras BOD sob temperaturas de 20 e $30^{\circ} \mathrm{C}$ por 12 horas.

Tabela 1 - Qualidade inicial de sementes de milho híbrido, cv. CO32, avaliadas pelo teor de água (TA), peso de mil sementes (PM), germinação (G), teste de tetrazólio viabilidade (TZ Viab.), primeira contagem do teste de germinação (PC), teste de frio (TF), teste de envelhecimento acelerado (EA), teor de água após envelhecimento acelerado (TAEA), teste de tetrazólio vigor (TZVig.), emergência de plântulas no campo (EC), índice de velocidade de emergência (IVE) e teste de condutividade elétrica (CE)

\begin{tabular}{cccccccccccc}
\hline TA & PM & G & TZ Viab. & PC & TF & EA & TAAE & TZ Vig. & EC & IVE & $\begin{array}{c}\text { CE } \\
(\%)\end{array}$ \\
\hline $\begin{array}{c}(\%) \\
7,8\end{array}$ & 28,0 & 94,0 & 92,0 & 85,0 & 95,0 & 33,0 & 25,1 & 87,0 & 91,0 & 7,4 & 22,0 \\
\hline
\end{tabular}


A massa das amostras foi monitorada mediante pesagens e, ao atingir a massa previamente calculada, foram retiradas 10 sementes por repetição para determinação do teor de água, acondicionando-se as restantes em frascos plásticos, mantidos à temperatura de $10^{\circ} \mathrm{C}$, por cinco dias, para uniformização do teor de água.

Posteriormente a submissão dos lotes de sementes aos tratamentos, procedeu-se as seguintes análises: teor de água, condutividade elétrica, porcentagens de plântulas normal obtidas na germinação e primeira contagem, e as massas secas da parte aérea e radicular total das plântulas normais quantificadas na primeira contagem.

Os dados foram submetidos à análise de variância, e as médias comparadas pelo teste de Tukey a 5\% de significância, independentemente para cada teor de água $(15 ; 20$ e $25 \%)$, sem transformação dos dados.

\section{Resultados e discussão}

Na Tabela 2 são apresentados os dados médios das variáveis avaliadas, em função de diferentes métodos e temperaturas de hidratação, para o teor de água de 15\%. O teor de água das sementes após o ajuste foi superior, quando utilizado o método da atmosfera úmida para hidratação. Esse resultado, provavelmente seja atribuída às variações metodológicas existentes devido ao maior tempo requerido para elevação do teor de água, exigindo pesagens em intervalos maiores (VILLELA et al., 2007; HAMPTON; TEKRONY, 1995), fato que dificultou a retirada das amostras com a massa próxima a calculada.

Após o período de uniformização, teores de água significativamente maiores foram observados com a utilização dos métodos da atmosfera úmida e de imersão em água. Teor de água inferior foi constatado com a adição da quantidade de água requerida. A adição de água, em pequenas quantidades pode levar a resultados imprecisos, além de provocar variações significativas no teor de água entre sementes da amostra, dependendo da posição da semente no recipiente onde a água foi adicionada (HAMPTON; TEKRONY, 1995).

A condutividade elétrica da solução de embebição das sementes variou com a temperatura e o método de hidratação adotado. Maior valor de condutividade elétrica foi constatado na temperatura mais elevada. A embebição por ser um processo físico, ocorre mais rapidamente em temperaturas elevadas reduzindo o período de embebição das sementes (GASPAR; NAKAGAWA, 2002; MARQUES et al., 2002). No entanto, a rápida embebição pode ocasionar danos à membrana celular, aumentando

Tabela 2 - Dados médios do teor de água após ajuste (TAA), teor de água após uniformização (TAU), condutividade elétrica (CE), primeira contagem do teste de germinação (PC), germinação (G), massa seca de parte aérea (MSPA), massa seca de raiz (MSR) e massa seca total de plântulas (MST) obtidas na primeira contagem do teste de germinação, de sementes de milho com teor de água de $15 \%$, embebidas sob diferentes métodos e temperatura

\begin{tabular}{|c|c|c|c|c|c|c|c|c|}
\hline Tratamento & TAA & TAU & $\mathrm{CE}$ & $\mathrm{PC}$ & $\mathrm{G}$ & MSPA & MSR & MST \\
\hline & $(\%)$ & $(\%)$ & $\left(\mu \mathrm{S} \mathrm{cm} \mathrm{cm}^{-1} \mathrm{~g}^{-1}\right)$ & $(\%)$ & $(\%)$ & (g/plântula) & (g/plântula) & (g/plântula) \\
\hline \multicolumn{9}{|c|}{ Temperatura } \\
\hline $20{ }^{\circ} \mathrm{C}$ & $15,0 \mathrm{a}$ & $15,2 \mathrm{a}$ & $19,11 \mathrm{~b}$ & $75 \mathrm{a}$ & $95 \mathrm{a}$ & $0,0071 \mathrm{a}$ & $0,0069 \mathrm{a}$ & $0,0141 \mathrm{a}$ \\
\hline $30{ }^{\circ} \mathrm{C}$ & $14,8 \mathrm{a}$ & $15,2 \mathrm{a}$ & $20,60 \mathrm{a}$ & $95 \mathrm{a}$ & $96 \mathrm{a}$ & $0,0087 \mathrm{a}$ & $0,0100 \mathrm{a}$ & $0,0187 \mathrm{a}$ \\
\hline \multicolumn{9}{|c|}{ Métodos } \\
\hline SU & $14,8 \mathrm{~b}$ & $15,1 \mathrm{~b}$ & $19,25 \mathrm{~b}$ & $96 \mathrm{a}$ & $97 \mathrm{a}$ & $0,0058 \mathrm{a}$ & $0,0072 \mathrm{a}$ & $0,0131 \mathrm{a}$ \\
\hline AU & $15,6 \mathrm{a}$ & $15,6 \mathrm{a}$ & $22,24 \mathrm{a}$ & $84 \mathrm{a}$ & $95 \mathrm{a}$ & $0,0091 \mathrm{a}$ & $0,0092 \mathrm{a}$ & $0,0184 \mathrm{a}$ \\
\hline IA & $14,5 \mathrm{~b}$ & $15,5 \mathrm{a}$ & $16,95 \mathrm{c}$ & $68 \mathrm{a}$ & $94 \mathrm{a}$ & $0,0093 \mathrm{a}$ & $0,0076 \mathrm{a}$ & $0,0169 \mathrm{a}$ \\
\hline AR & $14,7 \mathrm{~b}$ & $14,7 \mathrm{c}$ & $20,98 \mathrm{ab}$ & 92 & $95 \mathrm{a}$ & $0,0074 \mathrm{a}$ & $0,0098 \mathrm{a}$ & $0,0171 \mathrm{a}$ \\
\hline \multicolumn{9}{|c|}{ Valor de F } \\
\hline Temperatura(T) & $0,61^{\mathrm{ns}}$ & $0,06^{\text {ns }}$ & $6,60^{*}$ & $22,76^{*}$ & $1,03^{\mathrm{ns}}$ & $40,75^{*}$ & $99,98^{*}$ & $87,68 *$ \\
\hline Método (M) & $6,20 *$ & $17,76^{*}$ & $15,45^{*}$ & $8,77^{*}$ & $1,78^{\mathrm{ns}}$ & $43,45^{*}$ & $16,98^{*}$ & $21,34^{*}$ \\
\hline $\mathrm{T} * \mathrm{M}$ & $0,24^{\mathrm{ns}}$ & $0,03^{\mathrm{ns}}$ & $1,37^{\mathrm{ns}}$ & $9,29 *$ & $2,36^{\mathrm{ns}}$ & $3,03 *$ & $15,19^{*}$ & $9,60 *$ \\
\hline CV $(\%)$ & 3,80 & 1,90 & 8,30 & 13,70 & 3,28 & 8,82 & 10,24 & 8,50 \\
\hline
\end{tabular}

Médias seguidas por letras iguais, na coluna, não diferem entre si pelo teste de Tukey ao nível de $5 \%$ de significância; *Significativo ao nível de $5 \%$ de significância; $\mathrm{SU}=$ substrato úmido, $\mathrm{AU}$ = atmosfera úmida, $\mathrm{IA}=$ imersão em água e $\mathrm{AR}$ = água requerida 
a perda de solutos do interior das células, elevando, consequentemente, os valores de condutividade elétrica. Desta forma, os resultados observados podem estar associados à ocorrência de danos às sementes, em função da rápida embebição.

Em relação aos métodos, a atmosfera úmida proporcionou maiores valores de condutividade, contudo, sem diferir significativamente do método água requerida. A adição da quantidade de água requerida pode provocar danos por embebição nas membranas, que são os eventos iniciais das alterações degenerativas nas sementes (DELOUCHE, 2002). Além disso, esse método apresentou menor teor de água após a uniformização e, quanto menor o teor de água da semente, maior a desorganização do sistema de membranas, o que certamente contribuiu para os maiores valores de condutividade.

A ausência de danos por embebição, no método da imersão direta em água, pode estar relacionada à entrada de água através da camada negra, assim as sementes, devido à rápida hidratação do embrião, atingiram em curto período de tempo a massa requerida para o nível de umidade desejado (McDONALD et al., 1994). A lixiviação menor de solutos durante o processo de hidratação, também, poderia ter contribuído com os baixos valores de condutividade elétrica da solução de embebição das sementes após a hidratação pelo referido método.

A germinação não foi alterada pelos fatores estudados. No entanto, observou-se que os valores se apresentaram iguais ou superiores aos observados na determinação da qualidade fisiológica inicial do lote (94\%), fato também constatado por Rossetto e Marcos Filho (1995) com a elevação do teor de água em sementes de soja para $15 \%$, utilizando os métodos do substrato úmido e atmosfera úmida. Entretanto, os autores observaram que a embebição de sementes de soja, utilizando substrato úmido na proporção de 2,5 vezes a massa do papel para elevação do teor de água a $15 \%$, contribuiu para reduzir a germinação, conseqüência provável do excesso de água no substrato que provocou danos durante a embebição.

A interação entre os fatores estudados foi verificada para a primeira contagem do teste de germinação e as massas secas de parte aérea, radicular e total de plântulas (TAB. 3).

A redução da temperatura alterou o comportamento fisiológico das sementes com inferioridade de desempenho, observada na temperatura de $20{ }^{\circ} \mathrm{C}$ em comparação com $30{ }^{\circ} \mathrm{C}$, exceto para o método do substrato úmido na primeira contagem do teste de germinação e na massa seca da parte aérea, de raiz e total de plântulas, e para o método de adição da quantidade de água requerida, na primeira contagem de germinação. A menor porcentagem de germinação sob temperatura de $20{ }^{\circ} \mathrm{C}$, possivelmente, está associada à menor velocidade de embebição, pois a temperatura é um dos fatores ambientais que interfere no processo de hidratação de sementes (LIMA et al., 2006).

$\mathrm{Na}$ temperatura de $20{ }^{\circ} \mathrm{C}$ o método da atmosfera úmida promoveu maior velocidade de germinação

Tabela 3 - Primeira contagem do teste de germinação, massa seca de parte aérea, massa seca de raiz e massa seca total de plântulas obtidas de sementes de milho com teor de água de $15 \%$, em função da temperatura e dos métodos de embebição

\begin{tabular}{|c|c|c|c|c|}
\hline \multirow{2}{*}{ Temperatura } & \multicolumn{4}{|c|}{ Métodos } \\
\hline & SU & $\mathrm{AU}$ & IA & AR \\
\hline \multicolumn{5}{|c|}{ Primeira contagem do teste de germinação (\%) } \\
\hline $20{ }^{\circ} \mathrm{C}$ & 98 a A & $74 \mathrm{~b} \mathrm{~B}$ & $41 \mathrm{c} \mathrm{B}$ & $88 \mathrm{ab} \mathrm{A}$ \\
\hline $30{ }^{\circ} \mathrm{C}$ & 95 a A & 94 a A & 96 a $\mathrm{A}$ & 95 a A \\
\hline \multicolumn{5}{|c|}{ Massa seca da parte aérea (g) } \\
\hline $20{ }^{\circ} \mathrm{C}$ & 0,0056 с A & $0,0079 \mathrm{ab} B$ & 0,0084 a B & $0,0067 \mathrm{bc} \mathrm{B}$ \\
\hline $30{ }^{\circ} \mathrm{C}$ & $0,0061 \mathrm{c} \mathrm{A}$ & 0,0104 a A & 0,0102 a A & $0,0080 \mathrm{~b} \mathrm{~A}$ \\
\hline \multicolumn{5}{|c|}{ Massa seca de raiz $(\mathrm{g})$} \\
\hline $20{ }^{\circ} \mathrm{C}$ & 0,0071 a $\mathrm{A}$ & 0,0076 a B & 0,0046 b B & 0,0084 a B \\
\hline $30{ }^{\circ} \mathrm{C}$ & $0,0072 \mathrm{~b} \mathrm{~A}$ & 0,0109 a A & 0,0105 a A & 0,0112 a A \\
\hline \multicolumn{5}{|c|}{ Massa seca total $(\mathrm{g})$} \\
\hline $20{ }^{\circ} \mathrm{C}$ & 0,0128 a A & 0,0154 a B & 0,0130 a B & 0,0151 a B \\
\hline $30{ }^{\circ} \mathrm{C}$ & $0,0134 \mathrm{~b} \mathrm{~A}$ & 0,0213 a $\mathrm{A}$ & 0,0208 a A & 0,0192 a $\mathrm{A}$ \\
\hline
\end{tabular}

Médias seguidas por letras iguais, minúsculas na linha e maiúsculas na coluna, não diferem entre si pelo teste de Tukey ao nível de 5\% de significância; $\mathrm{SU}=$ substrato úmido, $\mathrm{AU}=$ atmosfera úmida, $\mathrm{IA}=$ imersão em água e $\mathrm{AR}=$ água requerida 
sem diferir significativamente do método de adição da quantidade de água requerida. A menor velocidade de germinação observada no método da atmosfera úmida decorre do longo período necessário para elevação do teor de água que, pode acelerar os processos de envelhecimento que acompanham o teor de água (VILLELA et al., 2003). Assim, os processos de envelhecimento ocorridos podem não ter afetado a capacidade de germinação, mas sim a velocidade desse processo. No caso da imersão direta, a menor velocidade de germinação possivelmente esteja associada à rápida absorção de água, principalmente pela região da camada negra que, hidratou inicialmente apenas o embrião (McDONALD et al., 1994), não promovendo a ativação enzimática e mecanismos de reparo, antes das sementes serem submetidas ao teste de germinação. Desta forma, tais processos foram completados durante o teste, reduzindo a velocidade do processo. Sob temperatura de $30{ }^{\circ} \mathrm{C}$, os métodos de atmosfera úmida e imersão em água destacaram-se nos parâmetros massa seca de parte aérea e total de plântulas obtida na primeira contagem do teste de germinação.

Na Tabela 4 são apresentados os dados dos parâmetros fisiológicos avaliados em sementes de milho com teor de água elevado para $20 \%$. O teor de água após ajuste e porcentagem de germinação não foram afetados pelos fatores em estudo. Entretanto, a porcentagem de germinação observada foi igual ou superior à determinada antes do processo de hidratação (94\%).

O teor de água após a uniformização foi alterado pelos métodos de hidratação, com valores inferiores para o método de adição da quantidade de água requerida. $\mathrm{O}$ resultado constatado corrobora os relatos de Hampton e Tekrony (1995), referentes à imprecisão do método.

Os métodos de hidratação alteraram os valores de condutividadeelétrica da soluçãodeembebição das sementes. O maior valor foi constatado no método da atmosfera úmida, sem diferença significativa do valor encontrado no método da adição da quantidade de água requerida. $\mathrm{O}$ processo de envelhecimento, cuja manifestação inicial é a degradação do sistema de membranas (CARVALHO, 1994; DIAS; MARCOS FILHO, 1995), pode ser o responsável pela elevação dos valores de condutividade no método da atmosfera úmida que, devido ao tempo requerido para a hidratação, pode desencadear o início do processo de deterioração das sementes (VILLELA et al., 2003).

No tratamento com adição da quantidade de água requerida, os valores de condutividade elétrica devem-se possivelmente, à ocorrência de danos por embebição que segundo Hampton e Tekrony (1995), constituiu-se em uma das limitações desse método.

Tabela 4 - Dados médios do teor de água após ajuste (TAA), teor de água após uniformização (TAU), condutividade elétrica (CE), primeira contagem do teste de germinação (PC), germinação (G), massa seca de parte aérea (MSPA), massa seca de raiz (MSR) e massa seca total de plântulas obtidas na primeira contagem do teste de germinação (MST), de sementes de milho com teor de água de $20 \%$, embebidas sob diferentes métodos e temperaturas

\begin{tabular}{|c|c|c|c|c|c|c|c|c|}
\hline \multirow{2}{*}{ Tratamento } & TAA & TAU & $\mathrm{CE}$ & $\mathrm{PC}$ & G & MSPA & MSR & MST \\
\hline & $(\%)$ & $(\%)$ & $\left(\mu \mathrm{S} \mathrm{cm} \mathrm{cm}^{-1} \mathrm{~g}^{-1}\right)$ & $(\%)$ & $(\%)$ & (g/plântula) & (g/plântula) & (g/plântula) \\
\hline \multicolumn{9}{|c|}{ Temperatura } \\
\hline $20{ }^{\circ} \mathrm{C}$ & $20,1 \mathrm{a}$ & $20,3 \mathrm{a}$ & $18,26 \mathrm{a}$ & $89 \mathrm{a}$ & $93 \mathrm{a}$ & $0,0086 \mathrm{~b}$ & $0,0094 \mathrm{~b}$ & $0,0180 \mathrm{~b}$ \\
\hline $30{ }^{\circ} \mathrm{C}$ & $20,2 \mathrm{a}$ & $20,4 \mathrm{a}$ & $18,05 \mathrm{a}$ & $92 \mathrm{a}$ & $93 \mathrm{a}$ & $0,0093 \mathrm{a}$ & $0,0106 \mathrm{a}$ & $0,0200 \mathrm{a}$ \\
\hline \multicolumn{9}{|c|}{ Métodos } \\
\hline SU & $20,1 \mathrm{a}$ & $20,3 \mathrm{ab}$ & $16,77 \mathrm{~b}$ & $93 \mathrm{a}$ & $94 \mathrm{a}$ & $0,0064 \mathrm{c}$ & $0,0077 \mathrm{c}$ & $0,0142 \mathrm{~d}$ \\
\hline $\mathrm{AU}$ & $20,6 \mathrm{a}$ & $20,6 \mathrm{a}$ & $20,69 \mathrm{a}$ & $92 \mathrm{ab}$ & $93 \mathrm{a}$ & $0,0103 \mathrm{a}$ & $0,0109 \mathrm{a}$ & $0,0212 \mathrm{~b}$ \\
\hline IA & $19,9 \mathrm{a}$ & $20,7 \mathrm{a}$ & $16,67 \mathrm{~b}$ & $92 \mathrm{ab}$ & $93 \mathrm{a}$ & $0,0109 \mathrm{a}$ & $0,0116 \mathrm{a}$ & $0,0226 \mathrm{a}$ \\
\hline AR & $19,9 \mathrm{a}$ & $19,9 \mathrm{~b}$ & $18,49 \mathrm{ab}$ & $86 \mathrm{~b}$ & $92 \mathrm{a}$ & $0,0082 \mathrm{~b}$ & $0,0099 \mathrm{~b}$ & $0,0181 \mathrm{c}$ \\
\hline \multicolumn{9}{|c|}{ Valor de F } \\
\hline Temperatura $(\mathrm{T})$ & $0,12^{\mathrm{ns}}$ & $0,35^{\mathrm{ns}}$ & $0,06^{\mathrm{ns}}$ & $2,44^{\mathrm{ns}}$ & $0,01^{\mathrm{ns}}$ & $11,76^{*}$ & $28,36^{*}$ & $37,65^{*}$ \\
\hline Método (M) & $0,78^{\mathrm{ns}}$ & $5,84^{*}$ & $4,99 *$ & $4,14^{*}$ & $0,28^{\mathrm{ns}}$ & $96,91^{*}$ & $56,54^{*}$ & $132,02 *$ \\
\hline $\mathrm{T} * \mathrm{M}$ & $0,17^{\mathrm{ns}}$ & $0,24^{\mathrm{ns}}$ & $0,46^{\mathrm{ns}}$ & $5,88^{*}$ & $0,70^{\mathrm{ns}}$ & $5,05^{*}$ & $37,00^{*}$ & $31,12 *$ \\
\hline $\mathrm{CV}(\%)$ & 5,21 & 2,05 & 13,14 & 5,24 & 4,12 & 6,67 & 6,46 & 4,83 \\
\hline
\end{tabular}

Médias seguidas por letras iguais, na coluna não, diferem entre si pelo teste de Tukey ao nível de $5 \%$ de significância; $*$ Significativo ao nível de $5 \%$ de significância; $\mathrm{SU}=$ substrato úmido, $\mathrm{AU}=$ atmosfera úmida, $\mathrm{IA}=$ imersão em água e $\mathrm{AR}=$ água requerida 
Os valores da interação entre os fatores estudados, verificada para a primeira contagem do teste de germinação e as massas secas de parte aérea, raiz e total de plântulas, são apresentados na Tabela 5.

Nos métodos de hidratação das sementes, os de substrato úmido, atmosfera úmida e imersão em água não alteraram as características avaliadas com a elevação da temperatura de 20 para $30{ }^{\circ} \mathrm{C}$. Contudo, o método de água requerida à temperatura de $20^{\circ} \mathrm{C}$ resultou em menor porcentagem de plântulas normais na primeira contagem do teste de germinação e menores massas secas da parte aérea, da raiz e do total de plântulas, o que possivelmente poderiam estar relacionadas ao menor teor de água das sementes após o período de uniformização do grau de umidade.

Os métodos da atmosfera úmida e da imersão em água sob temperatura de $20{ }^{\circ} \mathrm{C}$ não alteraram os parâmetros fisiológicos avaliados. No entanto, os métodos de imersão em água, de atmosfera úmida e da quantidade água requerida sob temperatura de $30{ }^{\circ} \mathrm{C}$ destacaram-se em relação ao método do substrato úmido quanto à massa seca da parte aérea, radicular e total das plântulas.

Não foi constatada interação entre os fatores temperatura e métodos de hidratação para todas as variáveis analisadas, quando o teor de água das sementes foi elevado para $25 \%$. A temperatura de hidratação também não alterou significativamente as variáveis, contudo foram observados efeitos para os métodos de hidratação (TAB. 6).
O método de adição da quantidade de água requerida resultou em menor teor de água das sementes tanto após o ajuste como após a uniformização, com diferenças superiores a $1 \%$ em relação aos demais, confirmando a imprecisão do método de hidratação conforme relatos de Hampton e Tekrony (1995).

A condutividade elétrica foi significativamente superior no método da atmosfera úmida, que demonstrou menor porcentagem de plântulas normais na primeira contagem e ao final do teste de germinação, diferindo significativamente dos demais. Este fato tem sido atribuído ao aumento do teor de água requerida, que prolongou ainda mais o tempo para que o mesmo fosse atingido por meio desse método. Entre outras causas, à degradação, em sementes deterioradas, de proteínas e carboidratos insolúveis, que constituem os principais compostos responsáveis pela absorção de água (VILLELA et al., 2007). Assim os processos deteriorativos que acompanham o aumento do teor de água foram acelerados afetando não apenas o vigor, mas também a capacidade germinativa das sementes.

Os métodos da atmosfera úmida e imersão em água resultaram em maiores volumes de massa seca, da parte aérea de plântulas, enquanto os métodos de imersão em água e adição da quantidade de água requerida promoveram maior massa seca de raiz. Contudo, quando se considerou a massa seca total de plântulas, apenas o substrato úmido diferiu-se dos demais, mostrando-se significativamente inferior.

Tabela 5 - Primeira contagem do teste de germinação, massa seca de parte aérea, massa seca de raiz e massa seca total de plântulas de sementes de milho com teor de água de $20 \%$, em função da temperatura e dos métodos de embebição

\begin{tabular}{|c|c|c|c|c|}
\hline \multirow{2}{*}{ Temperaturas } & \multicolumn{4}{|c|}{ Métodos } \\
\hline & SU & $\mathrm{AU}$ & IA & AR \\
\hline \multicolumn{5}{|c|}{ Primeira contagem do teste de germinação (\%) } \\
\hline $20{ }^{\circ} \mathrm{C}$ & $92 \mathrm{aA}$ & $94 \mathrm{aA}$ & $94 \mathrm{aA}$ & $79 \mathrm{bB}$ \\
\hline $30{ }^{\circ} \mathrm{C}$ & $95 \mathrm{aA}$ & $90 \mathrm{aA}$ & $91 \mathrm{aA}$ & $93 \mathrm{aA}$ \\
\hline \multicolumn{5}{|c|}{ Massa seca da parte aérea $(\mathrm{g})$} \\
\hline $20{ }^{\circ} \mathrm{C}$ & $0,0064 \mathrm{bA}$ & $0,0100 \mathrm{aA}$ & $0,0109 \mathrm{aA}$ & $0,0072 \mathrm{bB}$ \\
\hline $30^{\circ} \mathrm{C}$ & $0,0064 \mathrm{cA}$ & $0,0108 \mathrm{aA}$ & $0,0110 \mathrm{aA}$ & $0,0092 \mathrm{bA}$ \\
\hline \multicolumn{5}{|c|}{ Massa seca de raiz $(\mathrm{g})$} \\
\hline $20{ }^{\circ} \mathrm{C}$ & $0,0076 \mathrm{bA}$ & $0,0112 \mathrm{aA}$ & $0,0116 \mathrm{aA}$ & $0,0072 \mathrm{bB}$ \\
\hline $30{ }^{\circ} \mathrm{C}$ & $0,0077 \mathrm{cA}$ & $0,0106 \mathrm{bA}$ & $0,0116 \mathrm{abA}$ & $0,0126 \mathrm{aA}$ \\
\hline \multicolumn{5}{|c|}{ Massa seca total $(\mathrm{g})$} \\
\hline $20^{\circ} \mathrm{C}$ & $0,0140 \mathrm{bA}$ & $0,0211 \mathrm{aA}$ & $0,0226 \mathrm{aA}$ & $0,0144 \mathrm{bB}$ \\
\hline $30{ }^{\circ} \mathrm{C}$ & $0,0144 \mathrm{bA}$ & $0,0214 \mathrm{aA}$ & $0,0226 \mathrm{aA}$ & $0,0218 \mathrm{aA}$ \\
\hline
\end{tabular}

Médias seguidas por letras iguais, minúsculas na linha e maiúsculas na coluna, não diferem entre si pelo teste de Tukey ao nível de $5 \%$ de significância; $\mathrm{SU}$ = substrato úmido, $\mathrm{AU}$ = atmosfera úmida, $\mathrm{IA}$ = imersão em água e $\mathrm{AR}$ = água requerida 
Tabela 6 - Dados médios do teor de água após ajuste (TAA), teor de água após uniformização (TAU), condutividade elétrica (CE), primeira contagem do teste de germinação (PC), germinação (G), massa seca de parte aérea (MSPA), massa seca de raiz (MSR) e massa seca total de plântulas (MST), de sementes de milho com teor de água de 25\%, embebidas sob diferentes métodos e temperaturas

\begin{tabular}{|c|c|c|c|c|c|c|c|c|}
\hline \multirow{2}{*}{ Tratamento } & \multirow{2}{*}{ TAA $(\%)$} & \multirow{2}{*}{ TAU (\%) } & \multirow{2}{*}{$\mathrm{CE}(\mu \mathrm{S} / \mathrm{cm} / \mathrm{g})$} & \multirow{2}{*}{$\mathrm{PC}(\%)$} & \multirow{2}{*}{ G (\%) } & \multirow{2}{*}{$\frac{\text { MSPA }}{\text { (g/plântula) }}$} & \multirow{2}{*}{$\frac{\text { MSR }}{\text { (g/plântula) }}$} & \multirow{2}{*}{$\frac{\text { MST }}{\text { (g/plântula) }}$} \\
\hline & & & & & & & & \\
\hline \multicolumn{9}{|c|}{ Temperatura } \\
\hline $20{ }^{\circ} \mathrm{C}$ & $25,2 \mathrm{a}$ & $25,3 \mathrm{a}$ & $18,72 \mathrm{a}$ & $89 \mathrm{a}$ & $90 a$ & $0,0095 \mathrm{a}$ & $0,0111 \mathrm{a}$ & $0,0206 \mathrm{a}$ \\
\hline $30^{\circ} \mathrm{C}$ & $25,1 \mathrm{a}$ & $25,4 \mathrm{a}$ & $18,79 \mathrm{a}$ & $90 \mathrm{a}$ & $91 \mathrm{a}$ & $0,0097 \mathrm{a}$ & $0,0105 \mathrm{a}$ & $0,0202 \mathrm{a}$ \\
\hline \multicolumn{9}{|c|}{ Métodos } \\
\hline SU & $25,3 \mathrm{ab}$ & $25,4 \mathrm{a}$ & $15,51 \mathrm{~b}$ & $95 \mathrm{a}$ & $96 \mathrm{a}$ & $0,0069 \mathrm{c}$ & $0,0079 \mathrm{c}$ & $0,0147 \mathrm{~b}$ \\
\hline $\mathrm{AU}$ & $25,8 \mathrm{a}$ & $25,9 \mathrm{a}$ & $25,86 \mathrm{a}$ & $77 \mathrm{~b}$ & $79 \mathrm{~b}$ & $0,0110 \mathrm{a}$ & $0,0105 \mathrm{~b}$ & $0,0215 \mathrm{a}$ \\
\hline IA & $25,2 \mathrm{ab}$ & $25,9 \mathrm{a}$ & $15,76 \mathrm{~b}$ & $93 \mathrm{a}$ & $94 \mathrm{a}$ & $0,0116 \mathrm{a}$ & $0,0121 \mathrm{a}$ & $0,0236 \mathrm{a}$ \\
\hline $\mathrm{AR}$ & $24,2 \mathrm{~b}$ & $24,1 \mathrm{~b}$ & $17,90 \mathrm{~b}$ & $92 \mathrm{a}$ & $94 \mathrm{a}$ & $0,0089 \mathrm{~b}$ & $0,0129 \mathrm{a}$ & $0,0218 \mathrm{a}$ \\
\hline \multicolumn{9}{|c|}{ Valor de F } \\
\hline Temperatura $(\mathrm{T})$ & $0,04^{\mathrm{ns}}$ & $0,63^{\mathrm{ns}}$ & $0,01^{\mathrm{ns}}$ & $0,61^{\mathrm{ns}}$ & $0,22^{\mathrm{ns}}$ & $0,48^{\mathrm{ns}}$ & $4,26^{\mathrm{ns}}$ & $1,64^{\mathrm{ns}}$ \\
\hline Método (M) & $5,81 *$ & $26,25 *$ & $24,39 *$ & $31,53^{*}$ & $33,57 *$ & $69,03 *$ & $69,65 *$ & $5,03 *$ \\
\hline $\mathrm{T} * \mathrm{M}$ & $0,51^{\mathrm{ns}}$ & $0,53^{\mathrm{ns}}$ & $0,14^{\mathrm{ns}}$ & $1,11^{\mathrm{ns}}$ & $1,22^{\mathrm{ns}}$ & $1,00^{\mathrm{ns}}$ & $1,99^{\mathrm{ns}}$ & $1,53^{\mathrm{ns}}$ \\
\hline CV $(\%)$ & 3,29 & 1,84 & 14,83 & 4,56 & 4,14 & 7,60 & 6,95 & 11,34 \\
\hline
\end{tabular}

Médias seguidas por letras iguais, na coluna não, diferem entre si pelo teste de Tukey ao nível de $5 \%$ de significância; *Significativo ao nível de $5 \%$ de significância; $\mathrm{SU}$ = substrato úmido, $\mathrm{AU}$ = atmosfera úmida, $\mathrm{IA}=$ imersão em água e $\mathrm{AR}$ = água requerida

Considerando os resultados obtidos nos três teores de água avaliados, observa-se que o método da atmosfera úmida proporcionou maiores valores de condutividade elétrica em todos os teores enquanto os menores valores foram verificados com imersão direta em água. A atmosfera úmida resultou também menor porcentagem de germinação para sementes com $25 \%$ de umidade, porém nos menores teores de água a germinação não foi alterada pelos métodos de hidratação. Com relação à porcentagem de germinação na primeira contagem nos dois menores teores de água avaliados, os métodos não diferiram na temperatura de $30{ }^{\circ} \mathrm{C}$. Contudo, para a temperatura de $20{ }^{\circ} \mathrm{C}$ os métodos da atmosfera úmida e imersão em água para o teor de $15 \%$ e o método de adição de água para o teor de $20 \%$ mostraram-se significativamente inferiores. Para $25 \%$, menor velocidade de germinação foi proporcionada pelo método da atmosfera úmida.

A temperatura de hidratação de $30{ }^{\circ} \mathrm{C}$ mostrou-se superior a de $20{ }^{\circ} \mathrm{C}$ na maioria das variáveis analisadas para os três teores de água. Dentre os métodos analisados o método da imersão direta em água apresentou resultados superiores ou estatisticamente semelhantes aos demais para a maioria das variáveis em todos os teores de água avaliados. Além de não alterar a qualidade fisiológica das sementes este método mostrou-se mais prático e rápido que os demais quanto a sua execução. Já o método da atmosfera úmida, além de demorado, gerou maior imprecisão com relação ao teor de água pretendido e alterou a qualidade fisiológica das sementes, principalmente na hidratação para os maiores teores de água, mostrando-se inadequado para hidratação de sementes desta espécie, podendo comprometer os resultados e a confiabilidade dos testes.

\section{Conclusões}

1.O método da atmosfera úmida proporciona redução da qualidade fisiológica das sementes de milho nos três teores de água;

2. A temperatura de $30^{\circ} \mathrm{C}$ e o método da imersão direta em água não alteram a qualidade fisiológica das sementes de milho, mostrando-se adequados para a hidratação visando à elevação do teor de água para $15 ; 20$ e $25 \%$.

\section{Referências}

BECKERT, O. P.; SILVA, W. R. O uso da hidratação para estimar o desempenho de sementes de soja. Bragantia, v. 61, n. 01, p. 61-69, 2002.

BEWLEY, J. D.; BLACK, M. Seed physiology of development and germination. 2.ed. New York: Press, 1994. 445p.

BRASIL Ministério da Agricultura e Reforma Agrária. Regras para Análise de Sementes. Brasília: SNDA/ DNDV/ CLAV, 2009. 365p. 
CARVALHO, N. M.; NAKAGAWA, J. Sementes: ciência, tecnologia e produção. Jaboticabal: FUNEP, 2000. 429p.

CARVALHO, N. M. O conceito de vigor em sementes. In: VIEIRA, R. D., CARVALHO, N. M. Testes de vigor de sementes. Jaboticabal: FUNEP, 1994. p.1-30.

DELOUCHE, J. Germinação, deterioração e vigor da semente. Seed News, v. 06, n. 06, p. 24-31, 2002.

DIAS, M. C. L. L.; BARROS, A. S. R. Avaliação da qualidade de sementes de milho. Londrina: IAPAR, 1995. 43p.

DIAS, D. C. F. S.; MARCOS FILHO, J. Testes de vigor baseados na permeabilidade das membranas celulares: I - Condutividade elétrica. Informativo ABRATES. Londrina, v. 05, n. 01, p. 26-36, 1995.

GARNCZARSKA, M.; ZALEWSKI, T.; KEMPKA, M. Water uptake and distribution in germinationg lupine seeds studied by magnetic resonance imaging and NMR spectroscopy. Physiologia Plantarum, v. 130, n. 01, p. 23-32, 2007.

GASPAR, C. M.; NAKAGAWA, J. Teste de condutividade elétrica em função do período e da temperatura de embebição para sementes de milheto. Revista Brasileira de Sementes, v. 24, n. 02, p. 82-89, 2002.

HAMPTON, J. G.; TEKRONY, D. M. Controlled deterioration test. In: HAMPTON, J. G.; TEKRONY, D. M. Handbook of vigour test methods. Zurich: International Seed Testing Association, 1995. p. 70-78.

KIKUCHI, K. et al. Water uptake by beans observed by micromagnetic resonance imaging. Annals of Botany. v. 98, n. 03, p. 545-553, 2006.

LIMA, A. A.; CALDAS, R. C.; SANTOS, S. Germinação e crescimento de espécies de maracujá. Revista Brasileira de Fruticultura, v. 28, n. 01, p. 125-127, 2006.

MARQUES M. A.; PAULA, R. C.; RODRIGUES, T. J. D. Adequação do teste de condutividade elétrica para determinar a qualidade fisiológica de sementes de Jacarandá-da-Bahia (Dalbergia nigra (VELL.) Fr. All. Ex Benth). Revista Brasileira de Sementes, Pelotas, v. 24, n. 01, p. 271-278, 2002.

McDONALD, M. B.; SULLIVAN, J. L.; LAUER, M. J. The pathway of water uptake in maize seeds. Seed Science and Technology, v. 22, p. 79-90, 1994.
MEYER, C. J., STEUdLE, E.; PETERSON, C. A. Patterns and kinetics of water uptake by soybean seeds. Journal of Experimental Botany, v. 58, n. 03, p. 717-732, 2007.

NAKAGAWA, J. Testes de vigor baseados no desempenho de plântulas. In: KRZYZANOWSKI, F. C.; VIEIRA, R. D.; FRANÇA NETO, J. B. Vigor de sementes: conceitos e testes. Londrina: Informativo ABRATES, 1999. p. 2.1-2.24.

NAKAGAWA, J. Testes de vigor baseados na avaliação das plântulas. In: VIEIRA, R. D.; CARVALHO, N. M. (Ed.) Testes de vigor em sementes. Jaboticabal: FUNEP, 1994, p. 48-85.

ROSA, S. D. V. F. et al. Eficácia do teste de condutividade elétrica para uso em estudos de danos de secagem em sementes de milho. Revista Brasileira de Sementes, v. 22, n. 01, p. 54-63, 2000.

ROSSETTO, C. A. V., MARCOS FILHO, J. Comparação entre os métodos de envelhecimento acelerado e deterioração controlada para avaliação da qualidade fisiológica de sementes de soja. Scientia Agrícola, v. 52, n. 01, p. 99-105, 1995.

TERSKIKH, V. V. et al. Wateruptake and oil distribution during imbibition of seeds of western white pine (Pinus monticola Dougl. ex D. Don) monitored in vivo using magnetic resonance imaging. Planta, v. 221, n. 01, p. 17-27, 2005.

VILLELA, F. A.; MARCOS-FILHO, J.; NOVEMBRE, A. D. L. C. Estado energético da água na germinação de sementes de soja. Revista Brasileira de Sementes, v. 29, n. 01, p. 27-34, 2007.

VILLELA, F. A.; MARCOS-FILHO, J. ; NOVEMBRE, A. D. L. C. Estado energético da água na semente de milho no processo de germinação. Revista Brasileira de Sementes, v. 25, n. 01, p. 95-100, 2003.

WAGNER JÚNIOR, A. et al. Influência do pH da água de embebição das sementes e do substrato na germinação e desenvolvimento inicial do Maracujazeiro doce. Revista Brasileira de Agrociência, v. 12, n. 02, p. 231-236, 2006.

ZUCARELI, C. et al. Potencial fisiológico de sementes de milho hidratadas pelo método do substrato de papel toalha. Revista Brasileira de Sementes, v. 30, n. 03, p. 122-129, 2008. 